\title{
Quasi-static crush behaviour of environmentally friendly kenaf/wool epoxy composites elliptical tube
}

\author{
Mohamed Alkateb ${ }^{1}$, S.M. Sapuan ${ }^{1,2,3 *}$, Z. Leman$^{1}$, Mohammad Jawaid ${ }^{2}$ \\ and M R Ishak ${ }^{3,4}$ \\ ${ }^{1}$ Department of Mechanical and Manufacturing Engineering, Universiti Putra \\ Malaysia 43400 UPM, Serdang Selangor, Malaysia \\ ${ }^{2}$ Laboratory of Biocomposite Technology, Institute of Tropical Forestry and Research \\ Products (INTROP), Universiti Putra Malaysia 43400 UPM, Serdang Selangor, \\ Malaysia \\ ${ }^{3}$ Aerospace Manufacturing Research Centre (AMRC) Universiti Putra Malaysia \\ 43400 UPM, Serdang Selangor, Malaysia \\ ${ }^{4}$ Departments of Aerospace Engineering, Universiti Putra Malaysia, 43400 UPM, \\ Serdang, Selangor, Malaysia \\ *E-mail: sapuan@upm.edu.my
}

\begin{abstract}
This current study is to investigate the behaviour of the kenaf/wool natural fibre. Reinforced composite elliptical cones with different content of fibre for each of the two types separately in absorbing energy and the load capacity, the lack studies about the composite elliptical tube, our focus was on this shape of shells of effect content of fibre for each of the two types separately. Various fibre contents were considered, including $30 \mathrm{wt} \%, 35 \mathrm{wt} \%$ and $40 \mathrm{wt} \%$. The composite elliptical tubes were subjected to an axial quasi-static crushing test to achieve the study objectives; the methodology has been divided into three main sections concerning the problem statement, the first section is the mandrels preparation; the second section is specimen's fabrication process and finally is the crushing test. This study concerns the usage of the composite elliptical tube as a collapsible energy absorbing device within an automobile structure, which is supported at the distal end (i.e. the point of attachment) by a stronger structure and is designed to behave in a manner more similar to the quasi-static axial regular progressive mode. Therefore, quasi-static axial compression tests were performed on the tubes using INSTRON universal servohydraulic testing machine. The materials used in this study are polymer resin and kenaf/wool fibres. Environmentally friendly kenaf and wool fibre were used in this study due to several advantages such as environmentally benign, lightweight, low cost, no health risk, and availability. Results showed that including $30 \mathrm{wt} \%$ has a higher value of load- caring capacity and energy-absorption capability than including $35 \mathrm{wt} \%$ and including $40 \mathrm{wt} \%$. The results also show that the wool fibre has a higher value of load-carrying capacity and energy-absorption capability than kenaf fibre.
\end{abstract}

Keywords: Environmentally friendly materials; Elliptical cones; Energy absorption; Kenaf composites; Wool composites. 


\section{INTRODUCTION}

As part of the engineering application, the tubular structure provides a constant delay force during impact and constant deceleration throughout the stroke. In practical applications, such as automobiles, square tubes are not only energy-absorbing parts but also used as a load carrying structure. The reason for the widespread use of square tubes crushed in the axial direction is it has high specific energy and long stroke [1].

Geometric is introduced into the structural parts used to avoid crash failure. Crash structural stabilise is the process of stages of behaviour and reduction of the peak crash load. These structurals can be realised in different positions, shapes, quantities and sizes to improve the crush behaviour of the energy absorber. Altenhof et al. [2] study the effects of three different types of discontinuity (circle, slot ellipse) and peak crushing load on energy absorption capacity and crush the power efficiency of aluminium square tube. At present, synthetic fibres are used to strengthen composite materials in many kinds of industries. It is widely used in automotive, aerospace, construction and other fields [3, 4]. The glass fibres and carbon fibres used to strengthen the polymer composite materials are commonly used in many industries [5]. The matrix and fibre of composite materials which based on petroleum resources, long Sustainability is one of the most critical problems in the environment [6]. The morphology of the composite mixture form is very complicated, and recycling of the composite material is very difficult. Recycling appeared to be a viable strategy, but doing so will change the properties of the composite.

Therefore, environmentally available natural fibres are introduced as composite materials reinforcements, although it brings certain advantages to the environment, especially when composites are landfilled or incinerated [7]. Enjoy several benefits; it's natural fibre compared to synthetic fibres such as suitable specific strength, low density, low cost, biodegradability, high toughness, and minimal use of non-renewable resources [8].

Briefly, fibre types are categorized based on the origin of plants, animals or minerals. All plants fibres contain cellulose as the main structural component, but the animal fibre mainly consists of protein. Mineral-based natural fibres are included in asbestos minerals but are avoided by related health problems and banned in many countries. Also, keratin is distinguished from other fibre proteins because its structure has high physical and thermal stability, not only hydrogen bonding and van der Waals forces but also the high content of amino acid cysteine [9]. In particular, the composite structure of the microfiber matrix in wool plays an important role in determining the mechanical properties [10]. Also, relatively high concentrations of sulfur (3 - 4 wt.\%) and nitrogen (15 - $16 \mathrm{wt} . \%)$. Amino acid groups contribute to wool flammability [11]. Despite its advantages, the disposal of by-products from wool waste, especially raw wool with poor quality from coarse wool or agricultural farm breeding, is estimated at three million tons per year, causing serious environmental and economic problems [12].

Meanwhile, reducing fuel consumption in automobiles and aerospace Industry attracted attention to the lightweight energy absorbing structure. In response to this requirement, natural fibres are one suitable candidate. Natural fibre-reinforced polymers are growing rapidly because of its advantages, for example, mechanical properties, less abrasiveness to hardware, renewability, biodegradability, a decrease in weight, low density and cost, consider excellent properties suitable for various applications [13]. 
The availability of natural fibre such as hemp, kenaf, sisal, etc. in several countries of the world, moreover, from the viewpoint of cost, density, abrasion, recycling, renewable and biodegradability, It has several advantages over conventional reinforcements. The performance of the fibre reinforced composites mainly depends on the fibre matrix and the ability to transfer the load from the matrix to the fibre [14-17]. Also, natural fibre composite materials are applied with a wide energy absorption structure [18-20].

The energy absorption capacity of composite materials is important for improving human safety during a car crash. Energy absorption is affected by several parameters some of them; matrix type, fibre type, specimen shape, fibre volume fraction, specimen geometry, test speed and quantity of fibre etc. The change of these parameters can cause subsequent changes in the specific energy absorption (ES) value of the composite material up to twice [21]. Many surveys, crashworthiness is defined as the ability of a vehicle to save it's an occupant from harm in a sudden accident. Therefore, crashworthiness is an important factor in automobile and aeroplane design [22-24].

To understand the absorption of energy and failure modes, several parameters (e.g., shape and geometric shape) that affect the crashworthiness of the composite tube (e.g., average crash load, the peak load, crash force efficiency and specific energy absorption) are selected. Some of parameters values help the tube tested to avoid fast buckling have been determined in previous studies. Some researchers focus to determine the effects of various variables on energy absorbing capabilities of composite tubes materials especially, such as fibre types [25], fibre alignments [26], geometries [27], and test velocities [28] on the crashworthiness. Fiber content, among the important factors, affects the composite structure and its mechanical properties. ElShekel et al. [29], studied the effect of fibre content (20,30, 40, and $50 \%$ ) on bending, tensile and impacted properties of kenaf bast fibre reinforced TPU composites. Using the method of melting mixing and moulding were prepared composite samples, results showed that samples with $30 \%$ fibre content are the highest tensile modulus. As the fibre content increased, flexural strength and modulus improved. But fibre content increase caused a reduction in impact strength. Jawaid et al. [30], they concluded that the tensile properties increase with the amount of jute fibres increase in the hybrid composite Ismail AE et al. [31] studied the tensile strength of woven yarn kenaf fiber reinforced polyester composites. According to the result, it is indicated that fiber orientations played an important role in determining the ultimate tensile strength, when the fiber orientations increased. The change in fiber orientations insignificantly affected the modulus of elasticity, on the other hand, insignificant increment of tensile strength has been observed if the numbers of layers are increased. Umar et al. [32] studied the effect of accelerated weathering on tensile properties of kenaf reinforced high-density polyethyiene composites. The results show that the kenaf fibres do not improve the tensile strength of composites but do provide better stiffness. Also the accelerated weathering exposure deteriorates the composites. Un-weathering to composites show the tensile strength superior to that weathering composites due to the deteriorating tensile properties. Ibrahim, et al. [33] studied the mechanical and thermal properties of composites from unsaturated polyester filled with oil palm ash. They found the modulus was improved by incorporation of OPA fillers in UP matrix, there was a lack of tensile strength and flexural strength. However, the stiffness of the composite material increased relatively. Also, the thermal stability of the composite material increased as the OPA filler content increased.

Other studies on composite structures such as cones [34, 35] and tubes [36-39] to investigate the energy absorption capacity of these structures under different test 
conditions has been done. Researchers have found that high energy absorption is obtained during progressive crushing of the composite tubes and cones under axial load.

Limited studies on the use of kenaf and no previous studies on the use of wool in the thin-walled tube as an energy absorption tool. This research aims to create a new element of the design optimization of vehicle structures, represented by elliptical composite tubes shape for crashworthiness improvement. New material has been proposed to improve crashworthiness. The approach adds an animal fibre (wool) to the design composite material as a variable in the crashworthiness. The new material has been applied to the thin-walled elliptical tube, and acceptable results have been obtained. The composite elliptical tubes underwent to axial compression loads, correspondingly referred to as: (KRCEC), (WRCEC), respectively in this study.

\section{EXPERIMENTAL SETUP}

\section{Materials and Fabrication}

The hand lay-up method, follow to fabricated of composite elliptical cones with vertex angles equal to $0^{\circ}$ (elliptical tubing) specimens, the wet winding fabrication process was used to fabricate the non-woven kenaf and woven wool fibres for reinforced epoxy resin matrix. Figure 1 shows the materials used in this study (a) kenaf mat (b) sheep wool, wool woven. A 30-70\% ratio of reinforcement and unsaturated epoxy resin matrix was utilised for the kenaf/wool -matrix in the present study. The fibres (wool and kenaf) was passed through a resin bath, causing resin impregnation. Winding parameters were maintained at a constant level during the fabricated period and cured at room temperature $\left(30^{\circ} \mathrm{C}\right)$ for 72 hours to provide optimum hardness and shrinkage. All samples were fabricated under similar conditions and with a set quantity of 9-9.5 $\mathrm{mm}$ thicknesses. All the specimens were $230 \mathrm{~mm}$ high. The cone bottom and top end dimension (i.e., inner major radius $(a b=a t=79 \mathrm{~mm})$ and inner minor radius $(b b=b t=$ $58 \mathrm{~mm})$ ) were fixed. The samples were extracted from the template stage and left until completely dry. The second stage involved finishing the sample per the required dimensions. Cone mould was fabricated by using mild steel sheets. Then the sheets were bent and welded to form the elliptical cone with vertex angles equal to $0^{\circ}$ (elliptical tubing) shape specimens. Columns steel was inserted into these hollow moulds for support purpose. Steel sheets elliptical cross-section sheets were cut with diameters equal to the top and bottom diameters of the elliptical cone (elliptical tubing) and then fixed at the mould sides. The mould was made in a way that can be easily extracted from these composite elliptical cones after the completion of the fabrication process. Figure 2 displays the geometric shape of the fabricated steel mould and both test samples are ready for crushing test (kenaf/wool epoxy composite elliptical cones) they are referred to in this study (KRCEC), (WRCEC), respectively.

\section{Testing Procedure}

The quasi-static axial crushing tests were carried out using the universal digitalMaterial Testing Machine 25 Tones (MTS 810, Instron) (see Figure 3), The speed of the machine was fixed at $20 \mathrm{~mm} / \mathrm{min}$ for compressing all the specimens. The test was carried out to a crush length of about 70 to $80 \%$ of the total length $(230 \mathrm{~mm})$. Data on applied load and platen shortening were collected using a digital data collection system. The load and displacement were recorded by an automatic data acquisition system. 
Three tests were performed on each type of specimens. The total number of the samples is eighteen.

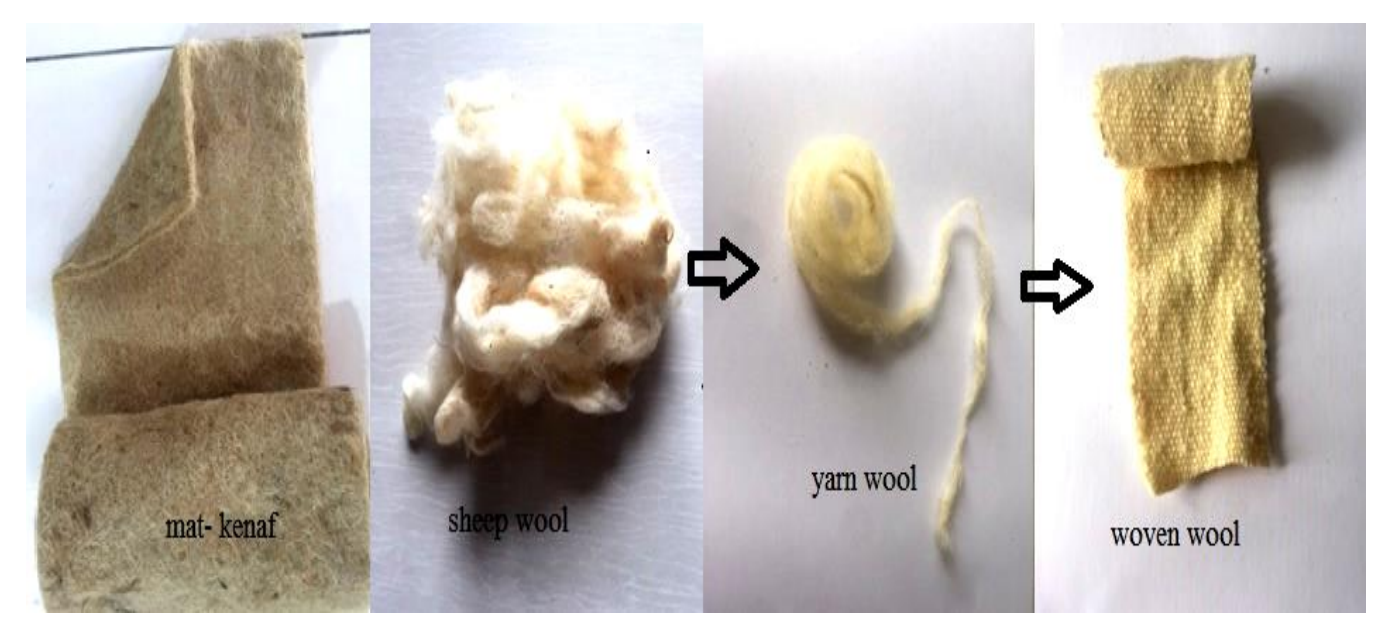

Figure 1. Materials used in this study. (a) kenaf mat (b) sheep wool, yarn and wool woven
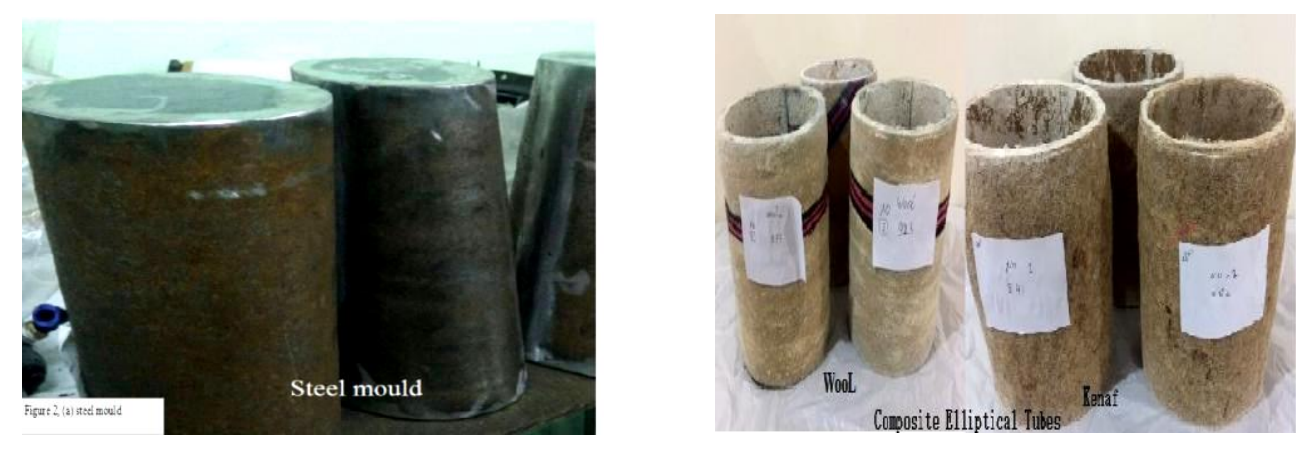

Figure 2. Steel mould and both test samples are ready for crushing test (WRCEC), (KRCEC).

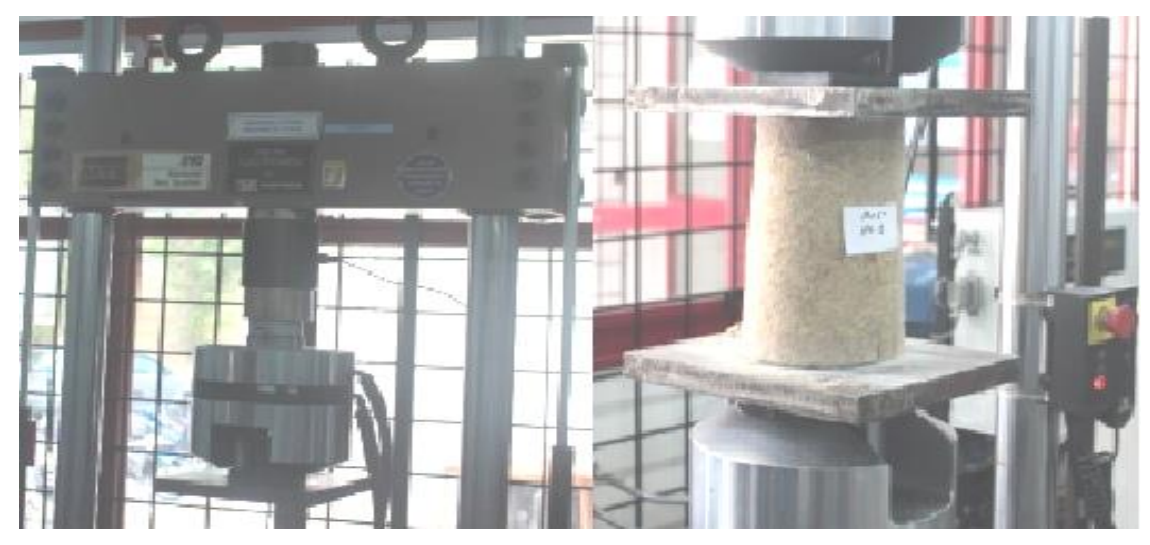

Figure 3. Instron machine types MTS 810 (25 Tones) and test fixture. 


\section{RESULTS AND DISCUSSION}

\section{Crashworthiness parameters}

From a crashworthiness perspective, it is necessary to design the vehicle so that a large amount of energy can be absorbed at the time of the accident. Energy absorption capacity can be estimated by knowing different parameters. load-displacement curve serves as an indication to determine the primary parameters as described in the following section.

\section{Mean-crushing Stress}

Mean crushing stress $(\sigma m)$ with the unit in $(M P a)$ can be defined as the average crushing load $(P m)$ divided by the original cross-sectional area $(A)$ of the energy absorber [40]. The mean is crushing stress $(\sigma m)$, whose value is calculated from the following mathematical Eq. (1):

$$
\sigma m=P m / A
$$

Where, $P m$ the average crushing load in $\mathrm{kN}, A$ original cross-sectional area in $\mathrm{mm}^{2}$.

\section{Crush Force Efficiency}

Crushing force efficiency (CFE) is an important factor in measuring crushing performance and evaluating the crashworthiness of energy absorbing parts [41,42]. The crushing force efficiency (CFE) of the composite can be defined as the average crushing load $\left(P_{m}\right)$ divided by the max crushing load $\left(P_{i}\right)$ whose value is calculated from the following mathematical Eq. (2):

$$
\mathrm{CFC}=\frac{p_{m}}{p_{i}}
$$

Where, $P_{i}$ the initial crushing load in $\mathrm{kN}, P_{m}$ the average crushing load in $\mathrm{kN}$.

This ratio should be close to $1(100 \%$ ) to avoid over stressing the material as it absorbs energy. The average load is proportional to the amount of energy absorbed, and the maximum load is proportional to the maximum deceleration. Therefore, the Crushing force efficiency parameter highlights the capacity to absorb energy while maintaining an acceptable deceleration.

\section{Initial crushing load $\left(P_{i}\right)$}

From the load-displacement curve can be obtained of the initial crushing load value directly, they are considered the first highest initial peak Load value reached before going down again, this has been recorded by Akbar et al. [43].

The efficiency of the crushing force decreased, the absorbing capacity also decreased, catastrophic failure occurred [44]. On the other hand, the maximum absorption capacity 
is obtained when the crushing force efficiency is high, because of the sample stabilized and harnesses more strength thus gaining more energy [45].

Depicted in Figure 9 includes the crushing force efficiency (CFE). In kenaf/wool epoxy composite elliptical tubes once the static crush started. The load drops clearly, with the low-value load the collapse continues. The ratio of the average load to the initial peak load is a considerable value to present the failure mechanism of the composite progressive or catastrophic failure mode. In contrast, the catastrophic failure mode is defined by low values of crushing force efficiency compared with the progressive failure, which was illustrated by wool samples.

The crushing force efficiency of wool composite elliptical tubes (WRCEC-30\%) is higher than that of kenaf composite elliptical tubes almost. This indicates that tufting increased the energy absorption by having a higher crushing force causing an increase in the average load compared to the initial peak load. The crushing force efficiency of wool composite elliptical tubes $(30 \%)$ is higher than for all other tested samples. The energy absorbed by the wool composite elliptical tubes (WRCEC(30\%)) is found higher than that obtained by the other tubes for all the tested tubes. Which shows a high value of load as initial peak load and an average load throughout the compressive test. Because the sample stabilizes and uses more load to gain more energy absorption is obtained [45]. Careful attention should be attention to its crush force efficiency (CFE) to evaluate the crashworthiness of energy absorbing devices [46].

As sum up, results showed the crushing force efficiencies values of $0.743,0.918$ and 1.223 were obtained by kenaf composite elliptical tubes (KRCEC) $(30 \%, 35 \%$ and $40 \%$ respectively) and crush force efficiencies values of 1.036, 1.054 and 0.769 was obtained by wool composite elliptical tubes (WRCEC) (30\%, 35\% and 40\%, respectively). In previous studies, that peak load was affected by the geometrical, material properties and characteristics of the tested specimen. As referred Hull [47] and Farley and Jones [48].

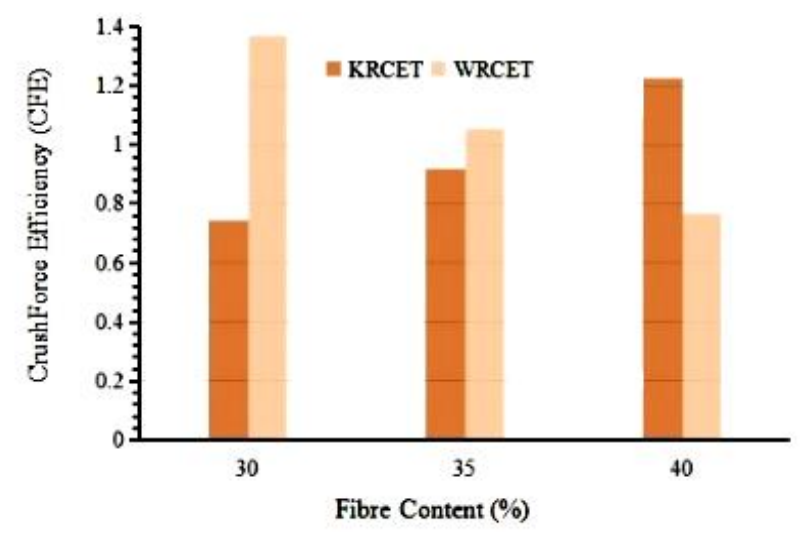

Figure 4. Crush force efficiency (CFE) characteristics for kenaf/wool epoxy composite elliptical tubes (error bars denote standard deviations).

\section{Specific energy absorption (Es)}

The specific energy absorption (Es) is the total energy absorbed (Et) per unit mass (m) of the structure absorbed $[49,50,51]$, which can be calculated from the following Eq. (3): 


$$
E s=E t / m
$$

The total of absorbed energy (Et) can be defined as the workpiece done, which is the crushing force that is represented by the area enclosed under the axis of the axial force versus the axial displacement curve and can be obtained by the following Eq. (4) :

$$
E t=W_{t}=\int_{s i}^{s b} P_{m} d s=P_{m}\left(S_{b}-S_{i}\right)
$$

Where, $w_{t}$ is the total energy absorbed, $s_{b}, s_{i}$ are the crush distances in $(\mathrm{mm}), p_{m}$ is the mean crush load as indicated in $(\mathrm{kN})$.

\section{The Effect of the Fiber Content on the Ability of Kenaf and Wool Fiber/Epoxy Composite Elliptical Tubes}

\section{Effect of the Wool Fiber Content}

\section{Effect Fiber Contents of 30\%}

The deformation process of a test specimen of a wool fibre/epoxy composite tube having a fibre content of $30 \%$ as shown in Figure 5. the first region started from $0 \mathrm{kN}$ and raised through the curve is semi-linear until it rises through the elastic zone and reaches the the initial crashing load $(\mathrm{Pi}) 22.827 \mathrm{kN}$ in the initial $44 \mathrm{~mm}$ displacement. The first part (beginning of crushing) of the load-displacement curve is relatively elastic. The displacement is related to the destructive deformation of the centre of the sample. The crack formation at the tube end is followed by an immediate drop of the compressive load, and its propagation parallel to the tube axis results the process of cracking the matrix began at the top of the structure.

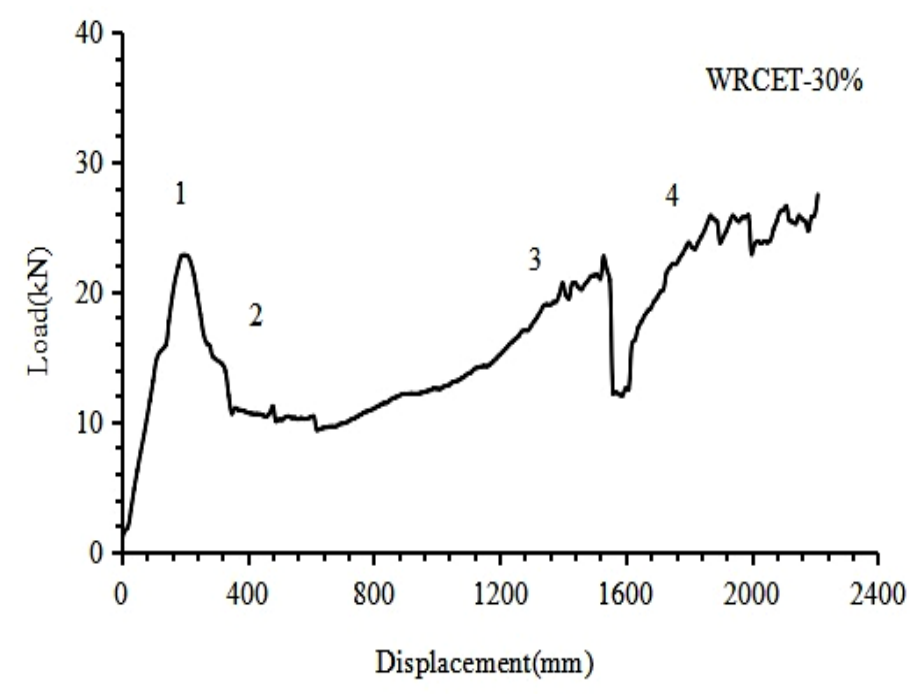

Figure 5. Compression history of wool fibre/epoxy composite elliptical tube for the $30 \%$. 


\section{Fiber Contents of $35 \%$}

The deformation process of a test specimen of a wool fibre/epoxy composite tube having a fibre content of $35 \%$ as shown in Figure 6 . The load-displacement curve is divided into two regions, the first region started from $0 \mathrm{kN}$ and raised through the curve is semi-linear until it rises through the elastic zone and reaches the first peak value of $11.927 \mathrm{kN}$ in the initial $44 \mathrm{~mm}$ displacement indicated (point 1). After this point, the curve is elastic when the plastic zone began to crush. Also, the curve decreased. Specifically, at this stage, the process of cracking the matrix began at the top of the structure, and there was a crack propagation. Subsequently, it dropped from $200 \mathrm{~mm}$, and $6.035 \mathrm{kN}$ of $4.10 \mathrm{kN}$ with a load-displacement curve of $410 \mathrm{~mm}$ displacement indicated (point 2), this is due to fracture of the matrix. The behaviour of the increased load-displacement curve was then achieved with a variation of about $11.60 \mathrm{kN}$ of 16.54 $\mathrm{kN}$ for $600 \mathrm{~mm}$ at $860 \mathrm{~mm}$ displacement (point 3). In the final stage (point 4) of the crushing, shown that the loading capacity increased, which is the sample act as a rigid material and thus increase the loading capacity and this cause to get more energy.

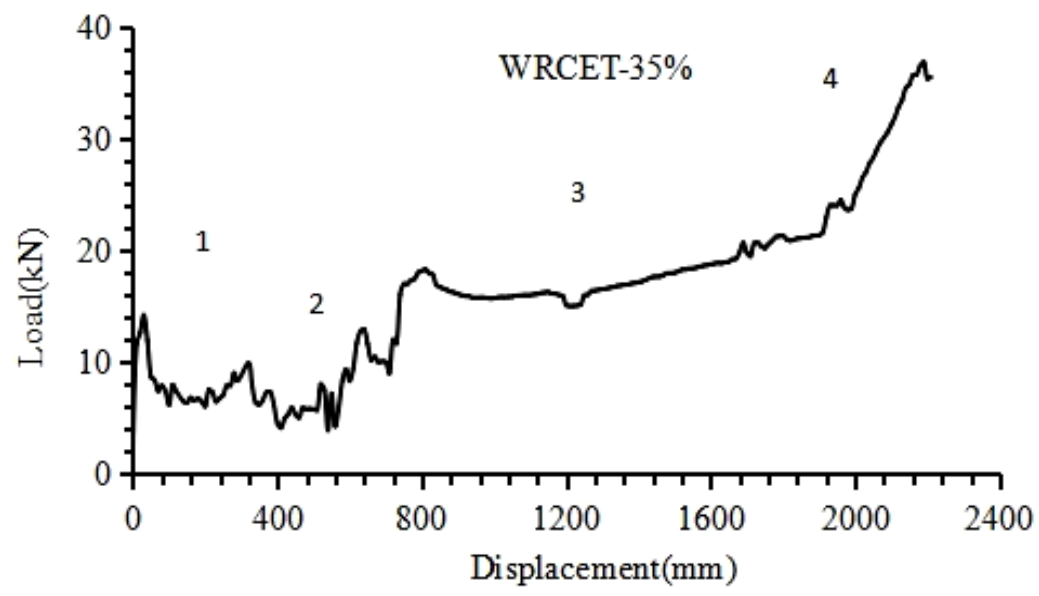

Figure 6. Compression history of wool fibre/epoxy composite elliptical tube for the $35 \%$.

\section{Fiber Contents of $40 \%$}

Figure 7 shows the deformation history of a mat kenaf/epoxy elliptical composite tubes with a fibre content of $40 \%$. These are subjected to quasi-static compression test at a fixed $(20 \mathrm{~mm} / \mathrm{sec})$ speed. It is precisely observed that the fibre structure fails. Because this ratio of fibres that began to rise to the matrix has made the crashing of the tube begins in a bulk mode with a high-stress concentration. It is characterized by longitudinal fracture, propagation of cracks and division of the tube wall in the transverse direction to the longitudinal tube axis.

Usually, this started at the top end of the compressed tube related to low crash energy absorption compared to the stable, progressive end of the crash. It can be seen that the gradual folding of buckling is characterized by the folding of the tube walls as in the case of ductile fibre reinforced materials with wrinkle generation. These wrinkles and buckles start and develop sequentially from one end of the tube under the buckling process. 


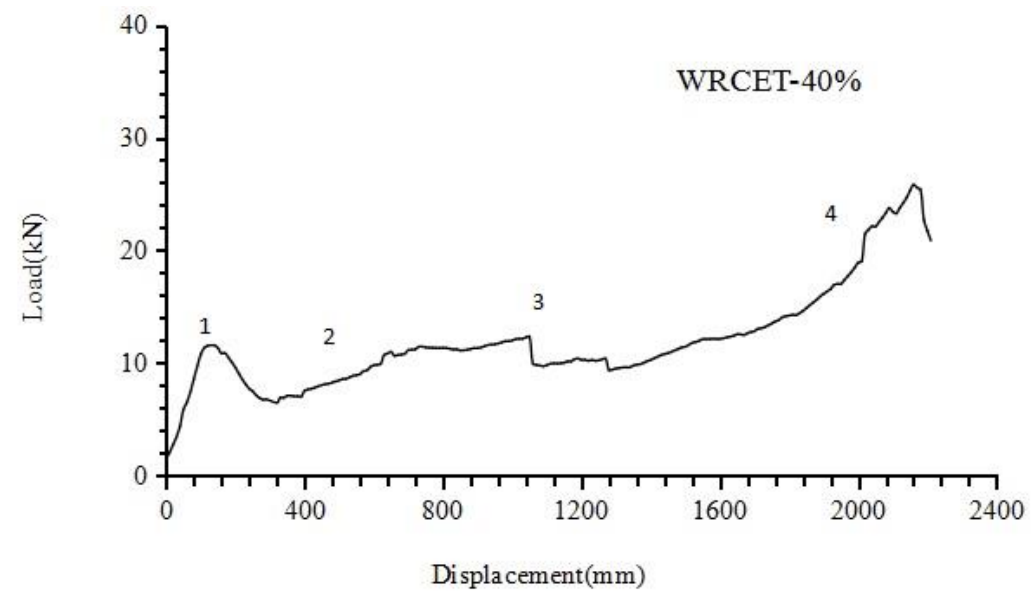

Figure 7. Compression history of wool fibre/ epoxy elliptical composite tube for the $40 \%$.

\section{Effect of the Kenaf Fiber Content}

\section{Fiber Contents of $30 \%$}

Figure 8 shows the compression history of a kenaf fibre composite elliptical tube having a fibre content of $30 \%$. It is shown that the load linearly increases before the start of matrix cracking started at the end of the tubing composite when the initial breaking load (Pi), is developed with $21.98 \mathrm{kN}$. Results for Tubes with fibre Contents of $30 \%$. This is the highest peak. Next, the transverse shear crack on the left side of the bottom end of the tube resulted in a decline in the load carrying capacity of the tube, reaching the lowest value of $11.19 \mathrm{kN}$ at $360 \mathrm{~mm}$ displacement. The tubing composite exhibited a stable behaviour. The last lock-up region follows the drop and the load increases linearly, the average crushing load $(\mathrm{Pm})$ value is $16.295 \mathrm{kN}$. The curve shows a stable behaviour of the tubing composite when it starts crushing until to the end of the test, and it was treated because the sample ran nearly one block. Such effects of the typical load-displacement curve in composite tubes had also been studied by Mahdi et al. [52] and Elfetori et al. [53].

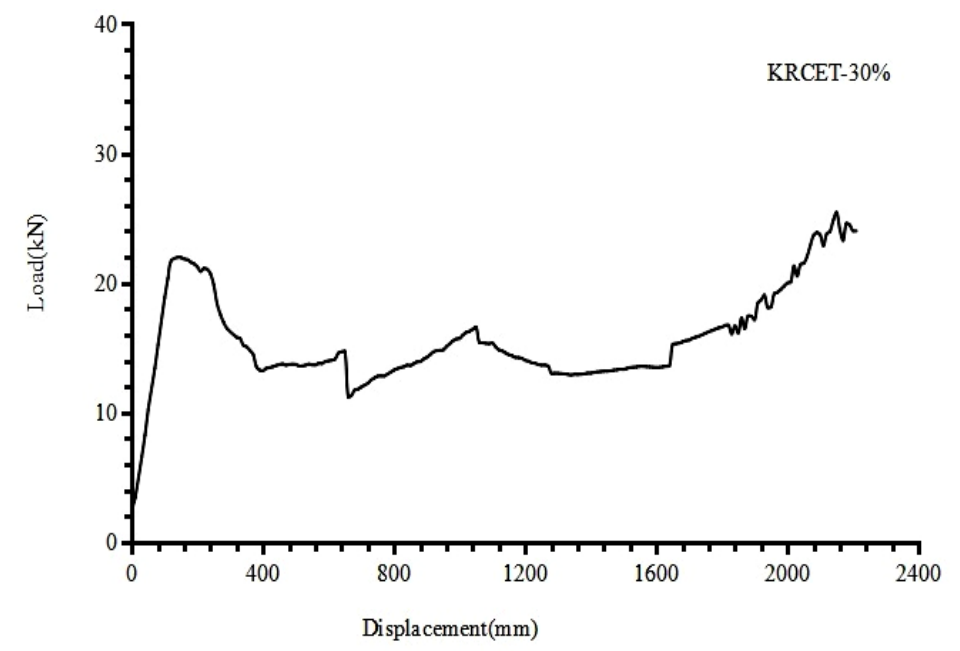

Figure 8. Compression history of kenaf fibre/epoxy composite elliptical tube for the $30 \%$. 


\section{Fiber Contents of $35 \%$}

Figure 9 shows the deformation history and load-displacement curve for tube composite with fibre contents of $35 \%$. The load increased as modifier linearly, to early-onset of matrix micro-cracking initiated at the ends of the tube. Also, Figure 9 shows linearly increasing deformation history up to the onset of the starting matrix at the end of the pre-loading micro crack tube composite and reads a tube composite load-displacement curve with a fibre content of $35 \%$. The deformation is divided into three stages, for the first phase, it increases linearly until the reaches as highest peak load value of 19.186 $\mathrm{kN}$ at $5 \mathrm{~mm}$. The second stage where the value of the load is markedly low and gets a lower value in load-carrying capacity was recorded. The load-displacement curve at the second stage is a result of progressive fibre debonding and cracking of the matrix. In the latter part of the load-displacement curve (the third stage), fluctuates and nonlinearly increase due to the sample conglomerate. As observed in the last region, the curve increases non-linearly, and the load is increased then decline again as shown in Figure. It was observed that this load-displacement curve was consistent with the previous study achieved by both Ribo and Nawawi [54].

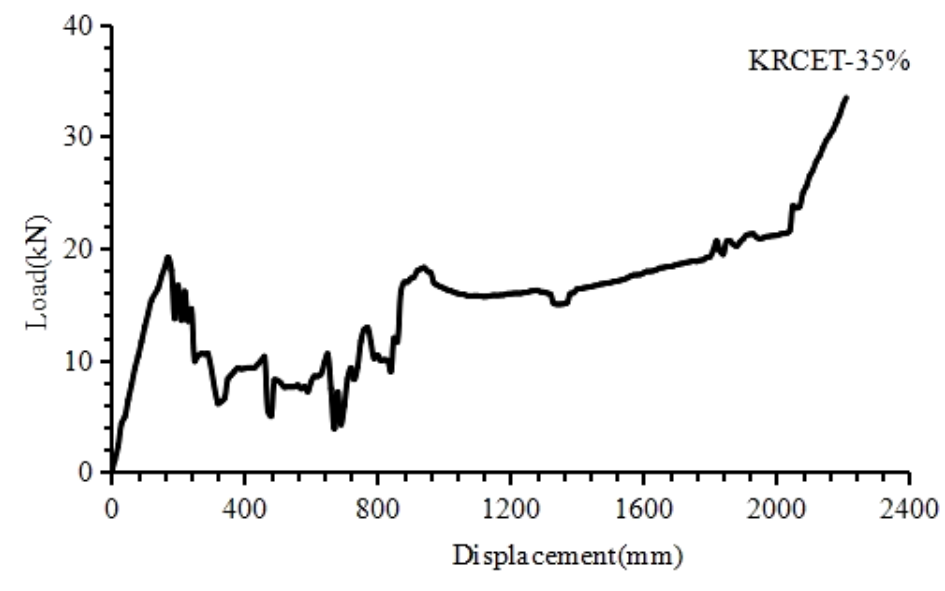

Figure 9. Compression history of kenaf fibre/ epoxy composite elliptical tube for the $35 \%$.

\section{Fiber Contents of $40 \%$}

Figure 10 shows the deformation history and the load-displacement curve of an elliptical tube composite having a fibre content of $40 \%$. In general, the compression and behaviour of the three different stages of the test sample from No. 1 to No. 3 shows a change in the behaviour of the elliptical tube composite at the onset of fracture eventually. It changes according to the situation and samples to another variable according to the factor indicated in the variable. Also, the first stage is specified by the elastic behaviour of the load (linear elasticity) until the first peak continues and the second phase in which energy (plateau stress) is lost until displacement. Finally, the third stage is characterised by a high proportion of energy dissipated in the fibre part (the sample conglomerate step). 


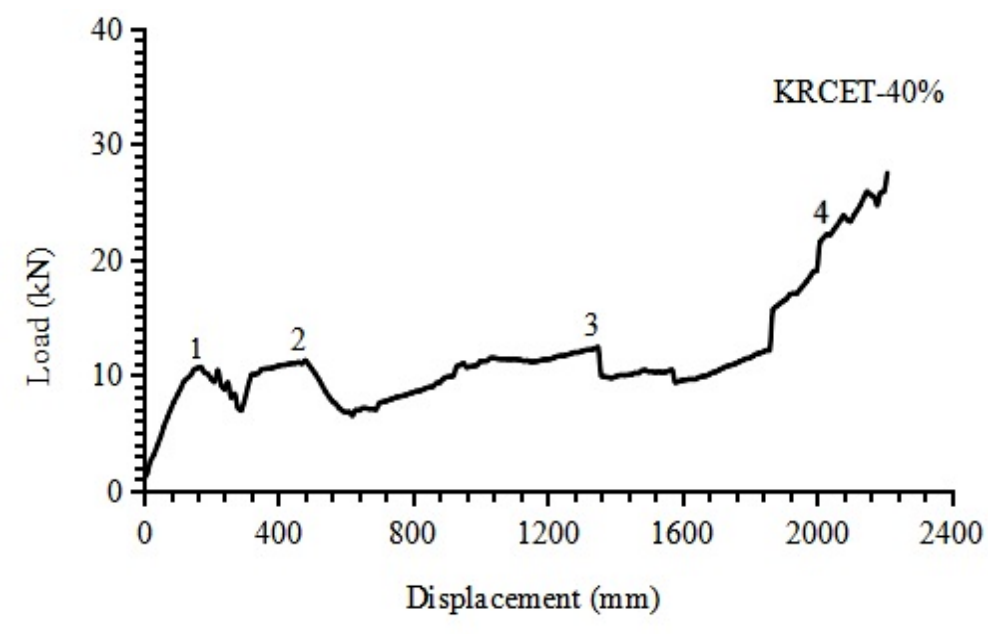

Figure 10. Compression history of kenaf fibre/ epoxy composite elliptical tube for the $40 \%$.

\section{Comparison between all the specimens}

The overall correlation of all samples (kenaf/epoxy composite elliptical tube and wool /epoxy composites elliptical tube) with $30 \%, 35 \%$ and $40 \%$ fibre content is shown in Figure 11. To achieve the goal of this experimentally study (the effects of the fiber content and fiber type) on the ability to absorb energy, has been addition quantity of kenaf and wool fibre to matrix, with the same ratios which have been added to formulate the composite elliptical tube structure, the same quantities of kenaf/wool fiber and the same manufacturing conditions to obtain satisfactory results, which refer to the wool/epoxy elliptical tube composite material with a fiber content of $30 \%$ has the highest compressive load of $22.827 \mathrm{kN}$, and at $198 \mathrm{~mm}$ compression displacement it is failure compared to all test specimens was also observed. In this research, there were two parameters only. Effect of fibre type (kenaf/wool) and effect fibre content with 30,35 and $40 \%$. Then elliptical tubes of kenaf/composite were manufactured, and their performance was compared with their elliptical tubes of wool/composite. The elliptical tube wool composite with $30 \%$ fibre had higher compressive properties.

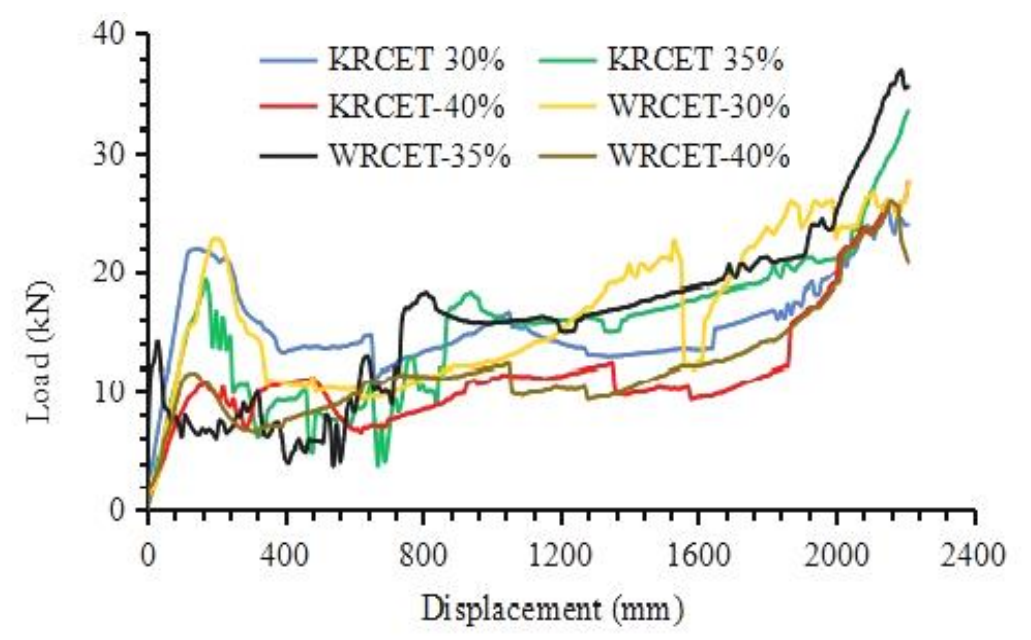

Figure 11. Compression history of kenaf fibre and wool fibre with 30,35and $40 \%$ unsaturated polymer for all elliptical tubes composite. 


\section{The primary crashworthiness parameters}

The primary crashworthiness parameters such as the initial crash load, the average crash load, the max crushing load, the crushing force efficiency, the stroke efficiency, and the amount of energy absorbed. Some of these parameters can be determined directly from the load-displacement curve (can be drawn directly from the experiment data, use the excel program ). The primary parameters and the primary regions are:

- Crash zones are the pre-crash stage, crash stages and the compaction stage.

- The initial crash load is can be determined directly from the curve. It is followed by a considerable reduction in the applied load.

- Average crash load (Pm) can be determined by averaging the crash loads applied throughout the post-crash stage.

Overall, the wool /epoxy elliptical composite tube record the highest value and then decreases when the fibre content increases as illustrated $22.95 \mathrm{kN}, 11.98 \mathrm{kN}$ and 11.56 $\mathrm{kN}$, respectively. Also the kenaf /epoxy elliptical composite tube record the highest value and then decreases when the fibre content increases as illustrated $21.11 \mathrm{kN}, 18.04$ $\mathrm{kN}$ and $10.35 \mathrm{kN}$, respectively. Figure 12 shows values of these parameters, which were recorded directly from the curves and the effect of the amount and type of fibre on these parameters.

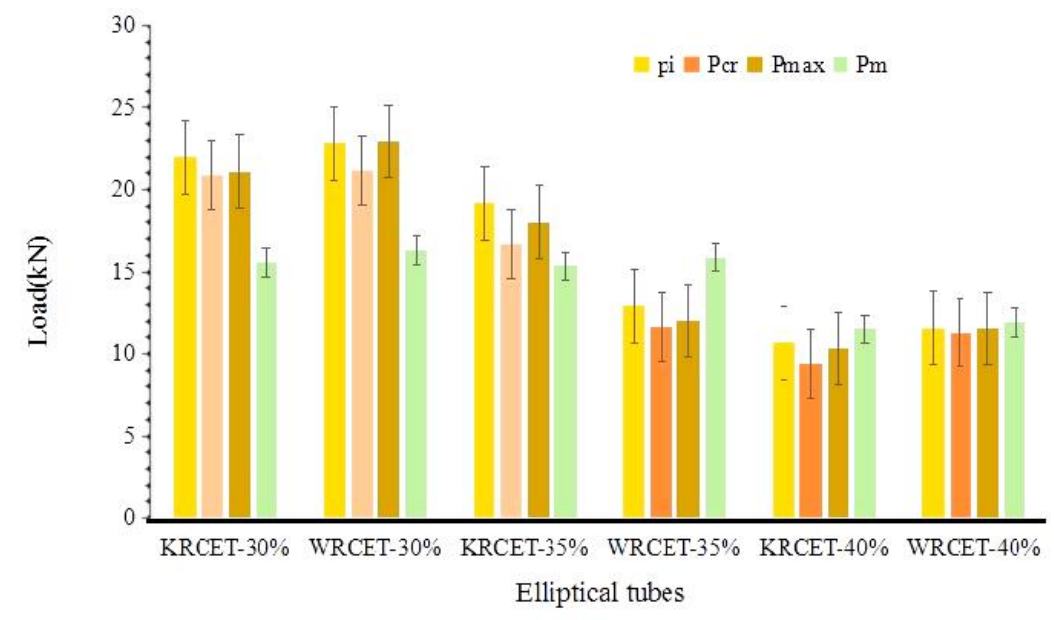

Figure 12. The effect of the fibre content on the ability of kenaf/wool fibre-reinforced elliptical epoxy composite tubes carry load values

\section{The Effect of the Fiber Content on the Ability of Kenaf and Wool Fiber/Epoxy Composite Elliptical Tubes to Absorb Energy}

It can be seen that the specific energy absorption decreased with the increase in the fibre content in Figure 13. During compression, the energy not absorbed by the fibre (wool/kenaf) reinforced elliptical composite tube is partially dissipated and is absorbed by the laminate.

The specific energy absorption values obtained depends on the area under the curve and to achieve the largest area must reach the average high strength and the longest crash stage. A crash stage is a stage followed by the pre-crash stage it is an important stage to absorb the amount of energy represented and the potential for the benefit of performance. It has been found that the specific energy absorbed by the wool composite elliptical tube with $30 \mathrm{wt} \%$ fiber content is higher than the specific energy obtained by the composite elliptical tube for all the tubes examined, the specific energy absorption values at $235.6462 \mathrm{~kJ} / \mathrm{kg}, 196.3695 \mathrm{~kJ} / \mathrm{kg}$ and $148.1387 \mathrm{~kJ} / \mathrm{kg}$ were obtained by wool 
elliptical composite tubes, respectively. And the maximum specific energy absorption value at $202.6942 \mathrm{~kJ} / \mathrm{kg}, 186.5317 \mathrm{~kJ} / \mathrm{kg}$ and $137.1748 \mathrm{~kJ} / \mathrm{kg}$ were obtained by kenaf elliptical composite tubes, respectively.

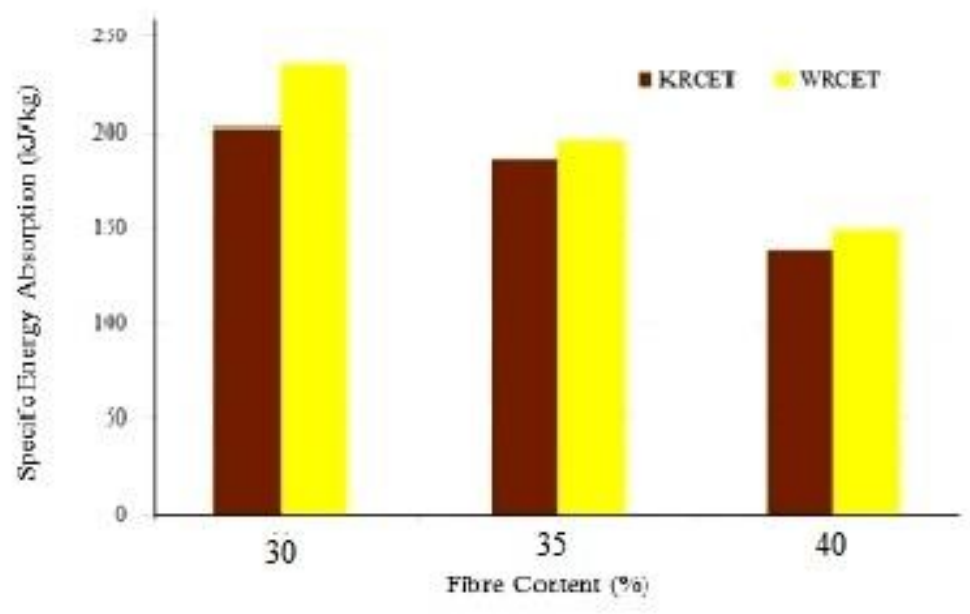

Figure 13. Specific Energy absorption of the axially crushed kenaf composite elliptical tubes and wool composite elliptical tubes

\section{CONCLUSIONS}

In this paper, non-woven kenaf and woven wool are used to fabricate elliptical epoxy composite tubes, with the same dimensions and different of content fibres and their effect on the ability to absorb energy and comparing wool composite elliptical tubes with kenaf elliptical composite tubes and find the best. In this process, two keys parameters fibre type and content) were employed. The main conclusions obtained from this paper are as follows:

1. This research aims to create a new element of the design optimization of vehicle structures, represented by elliptical composite tubes shape for crashworthiness improvement. New material has been proposed to improve crashworthiness. The approach adds an animal fibre to the design of composite material including fibre type (wool) as a variable in the crashworthiness.

2. Maximum axial load of the wool /epoxy elliptical composite tube record the highest value and then decreases when the fibre content increases as illustrated $22.95 \mathrm{kN}, 11.98$ $\mathrm{kN}$ and $11.56 \mathrm{kN}$, respectively. Also a maximum axial load of the kenaf /epoxy elliptical composite tube record the highest value and then decreases when the fibre content increases as illustrated $21.11 \mathrm{kN}, 18.04 \mathrm{kN}$ and $10.35 \mathrm{kN}$, respectively.

3. The specific energy absorption values of $235.6462 \mathrm{~kJ} / \mathrm{kg}, 196.3695 \mathrm{~kJ} / \mathrm{kg}$ and $148.1387 \mathrm{~kJ} / \mathrm{kg}$ were obtained by wool elliptical composite tubes, respectively. And the maximum specific energy absorption value of $202.6942 \mathrm{~kJ} / \mathrm{kg}, 186.5317 \mathrm{~kJ} / \mathrm{kg}$ and $137.1748 \mathrm{~kJ} / \mathrm{kg}$ were obtained by kenaf elliptical composite tubes, respectively.

4. The crushing force efficiencies values of $0.743,0.918$ and 1.0223 were obtained by kenaf composite elliptical tubes (KRCEC) (30\%, 35\% and 40\% respectively). Crush force efficiencies values of $1.336,1.054$ and 0.769 were obtained by wool composite elliptical tubes (WRCEC) (30\%, 35\% and 40\%, respectively).

5. This research is a primary attempt at using wool as an energy absorber. Authors are working on different of fibre content for weight to obtain the critical content. 
Catastrophic failure mode occurs when the low value of the crushing force efficiency when peak load (Pi) is greater than average load (Pm).

6. Catastrophic failure mode occurs when the low value of the crushing force efficiency when peak load $(\mathrm{Pi})$ is greater than average load $(\mathrm{Pm})$.

It has been noted that energy absorbed depends on the fibre content (30 wt $\%$, $35 \mathrm{wt} \%$ and $40 \mathrm{wt} . \%$ ), for each of the wool/ kenaf tubes composites.

7. Natural fibres (wool/kenaf) have opened the possibilities for continuous fibre composite applications.

8. It has been noted that energy absorbed depends on the fibre content ( $30 \mathrm{wt} \%, 35 \mathrm{wt} \%$ and $40 \mathrm{wt} . \%$ ), for each of the wool/ kenaf tubes composites. The fibre content of $30 \%$ by weight of the wool composite tube tends to absorb more energy during crushing due to the longest distance in the crush zone.

Further work could be carried out to generate more data such as changing the crushing speed and different matrix resin types etc.

\section{ACKNOWLEDGEMENTS}

The authors want to thank the Universiti Putra Malaysia for the financial support for this research programme using HiCoE Grant, Ministry of Higher Education, Malaysia.

\section{REFERENCES}

[1] Oshkovr SA, Taher STA, Eshkoor R, Ariffin AK, Azhari CH. Energyabsorption and failure response of silk/epoxy composite square tubes: Experimental. Composites Part B: Engineering. 2012; 43:542-48.

[2] Altenhof William Li Li, Cheng Qingwu. Experimental investigation on the crush behaviour of AA 6061-T6 aluminium square tubes with different types of through-hole discontinuities. International Journal of Thin-Walled Structures.2006; 44:441-54.

[3] Hambali A, Sapuan SM, Ismail N, Nukman Y. Material selection of polymeric composite automotive bumper beam using analytical hierarchy process. Journal of Central South University of Technology. 2010; 17: 244-56.

[4] Sapuan SM, Maleque MA, Hameedullah M, Sudden MN, Ismail N. A note on the conceptual design of the polymeric composite automotive bumper system. Journal of Materials Processing Technology. 2005; 159:145-51.

[5] Hambali A, Sapuan SM, Ismail N, Nukman Y. Application of analytical hierarchy process in the design concept selection of automotive composite bumper beam during the conceptual design stage. Scientific Research and Essays.2009; 4:198-211.

[6] Sastra HY, Siregar JP, Sapuan SM, Hamdan MM. Tensile Properties of Arengapinnata Fiber-Reinforced Epoxy Composites. Polymer- Plastice Technology and Engineering. 2006;45:149-55.

[7] Rashdi AAA, Sapuan SM, Ahmad MMHM, Khalina A. Water absorption and tensile properties of soil buried kenaf fibre reinforced unsaturated polyester composites. Journal of Food, Agriculture \& Environment.2009; 7:908-11.

[8] Leman Z, Sapuan SM, Azwan M, Ahmad MMHM, Maleque MA. The effect of environmental treatments on fibre surface properties and tensile strength of 
sugar palm ibre-reinforced epoxy composite. PolymerPlastics Technology and Engineering. 2008;47:606.

[9] Martínez- Hernández, AL, Velasco-Santos C, Icaza M, Castaño VM. Mechanical properties evaluation of new composites with protein fibres reinforcing poly(methyl methacrylate). Polymer. 2005; 46:8233-8.

[10] Tsobkallo K, Aksakal B, Darvish D. Analysis of the contribution of the microfibrils and matrix to the deformation processes in wool fibers. Journal of Applied Polymer Science. 2012; 125:168-79.

[11] Price D, Horrocks AR. Polymer degradation and the matching of FR chemistry to degradation. In: Wilkie CA, Morgan $\mathrm{AB}$, editors. Fire retardancy of polymeric materials. New York: CRC Press. 2010; p:15-38.

[12] Tonin C, Zoccola M, Aluigi A, Varesano A, Montarsolo A, Vineis C. Study on the conversion of wool keratin by steam explosion. Biomacromolecules. 2006; 7:3499-504.

[13] Mallick PK. Fiber Reinforced composites, Third Edition; 2008

[14] Arthanarieswaran VP, Umaravel AK, Athirselvam MK. Evaluation of mechanical properties of banana and sisal fiber reinforced epoxy composites: Influence of glass fiber hybridization, Materials and Design. 2014; 64:194-202.

[15] Jeyanthi S, Janci Rani J. Improving Mechanical Properties by Kenaf Natural Long Fiber Reinforced Composite for Automotive Structures. Journal of Applied Science and Engineering. 2012;15:275-80.

[16] Yihui Pan, Zheng Zhong. A nonlinear constitutive model of unidirectional natural fiber Reinforced composites considering moisture absorption. Journal of the Mechanics and Physics of Solids. 2014;69:132-42.

[17] Alkbir MFM. Sapuan SM, Nuraini AA, Ishak MR. Effect of geometry on crashworthiness parameters of natural kenaf fibre reinforced composite hexagonal tubes. Materials and Design. 2014;60:85-93.

[18] El-Shekeil YA, Sapuan SM, Abdan K, Zainudin ES. Influence of fiber content on the mechanical and thermal properties of Kenaf fiberreinforced thermoplastic polyurethane composites. Materials and Design.2012;40:299303.

[19] Elsaid A, Dawood M, Seracino R, Bobko C. Mechanical properties of kenaf fiber reinforced concrete. Const Build Mater. 2011;25:1991-2001.

[20] Sapuan SM, Bachtiar D. Mechanical properties of sugar palm fibre reinforced high impact polystyrene composites. Procedia Chem. 2012;4:101-6.

[21] Jacob GC, Fellers JF, Simunovk S, Sarbuck JM. Energy Absorption in Polymer Composites for Automotive Crashworthiness. Journal of Composite Materials. 2002; 36:813-50.

[22] Alkateb M, Mahdi E, Hamouda A, Hamdan M. On the energy absorption capability of axially crashed composite elliptical cones. Composite structures 2004; 66:495-501.

[23] Lau ST, Said M, Yaakob MY. On the effect of geometrical designs and failure modes in composite axial crashing: A literature review. Composite structures. 2012; 94:803-12.

[24] Palanivelu S, Van Paepegem W, Degrieck J, Kakogiannis D, Van Ackeren J, Van Hemelrijck D. Comparative study of the quasi-static energy absorption of small-scale composite tubes with different geometrical shapes for use insacrificial cladding structures. Polymer testing. 2010;29:381-96.

[25] Mahdi E, Sebaey TA. An experimental investigation into crushing behavior ofradially stiffened GFRP composite tubes. Thin-Walled Struct. 2014;76:8-13. 
[26] Mahdi E, Hamouda AMS, Sebaey TA. The effect of fiber orientation on the energy absorption capability of axially crushed composite tubes. Materials \& Design. 2014;56:923-28.

[27] Palanivelu S, Van Paepegem W, Degrieck J, Vantomme J, Kakogiannis D, VanAckeren J. Comparison of the crushing performance of hollow and foamfilled small-scale composite tubes with different geometri cal shapes for use in sacrificial cladding structures. Composites Part:B. 2010;41:434-45.

[28] Costas M, Diaz J, Romera LE, Hernandez S, Tielas A. Static and dynamic axial crushing analysis of car frontal impact hybrid absorbers. International Journal of Impact Engineering. 2013;62:166-81.

[29] El-Shekeil Y, Sapuan SM, Algrafi M. Effect of fiber loading on mechanical and morphological properties of cocoa pod husk fibers reinforced thermoplastic polyurethane composites. Materials \& Design. 2014;64:330-33.

[30] Jawaid M, Khalil HA, Hassan A, Dungani R, Hadiyane A. Effect of jute fiber loading on tensile and dynamic mechanical properties of oil palm epoxy composites. Composites Part B: Engineering. 2013; 45:619-24.

[31] Ismail AE, Che Abdul Aziz MA. Tensile strength of woven yarn kenaf fiber reinforced polyestercomp osites, Journal of Mechanical Engineering and Sciences (JMES). 2015; 9:1695-704.

[32] Umar AH, Zainudin ES, Sapuan SM. Effect of accelerated weathering on tensile properties of kenaf reinforced high-density polyethylene composites. Journal of Mechanical Engineering and Sciences (JMES). 2012; 2:198-205.

[33] Ibrahim MS, Sapuan SM, Faieza AA. Mechanical and thermal properties of composites from unsaturated polyester filled with oil palm ash. Journal of Mechanical Engineering and Sciences (JMES). 2012; 2:133-147.

[34] Kathiresan M, Manisekar K, Manikandan V. Performance analysis of fibre metal laminated thin conical frusta under axial compression. Composite Structures. 2012; 94, 3510-19

[35] Kathiresan M, ManisekarK, Manikanda V. Crashworthiness analysis of glass fibre/epoxy laminated thin walled composite conical frusta under axial compression. Composite Structures. 2014;108:584-99.

[36] Eshkoor RA, Ude AU, Oshkovr SA, Sulong AB, Zulkifli R. Ariffin AK, Azhari $\mathrm{CH}$. Failure mechanism of woven natural silk/epoxy rectangular composite tubes under axial quasi-static crushing test using trigger mechanism. International Journal of Impact Engineering. 2014; 64:53-61.

[37] Oshkovr SA, Eshkoor RA, Taher ST, Ariffin AK, Azhari CH. Crashworthiness characteristics investigation of silk/epoxy composite square tubes. Composite Structures. 2012; 94:2337-2342.

[38] Mirzaei M, Shakeri M, Sadighi M, Akbarshahi H. Experimental and analytical assessment of axial crushing of circular hybrid tubes under quasi-static load. Composite Structures. 2012; 94:1959-66.

[39] Kashani MH, Alavijeh HS, Akbarshahi H, Shakeri M. Bitubular square tubes with different arrangements under quasi-static axial compression loading. Materials \& Design. 2013; 51:1095-03.

[40] Kavi H, Toksoy AK, Gudan M. Predicting energy absorption in foam filled thin-walledaluminium tubes based on experimentally determined strength coefficent. Materials \& Design. 2006; 27:263-9.

[41] Eshkoor RA, Oshkovr SA, Sulong AB, Zulkifli R, Ariffin AK, Azhari CH. Comparative research on the crashworthiness characteristics of woven natural silk/epoxy composite tubes. Materials \& Design. 2013;47: 248-57. 
[42] Oshkovr SA, Eshkoor RA, Taher ST, Ariffin AK, Azhari CH. Crashworthiness characteristics investigation of silk/epoxy composite square

[43] Alkbir MFM, Sapuan SM, Nuraini AA, Ishak MR. Effect of geometry on crashworthiness parameters of natural kenaf fibre reinforced composite hexagonal tubes. Materials \& Design. 2014; 60:85-93.

[44] Guoxing L, Tongxi Y. Energy absorption of structures and materials. Woodhead Publishing; 1st edition. 2003.

[45] Tarlochan F, Ramesh S. Composite sandwich structures with nested inserts for energy absorption application. Composite Structures. 2012; 94: 904-16.

[46] Blicblau A, Coutts R, Sims A. Novel composites utilising raw wool and polyester resin. Journal of Materials Science Letters. 1997; 16:1417-19.

[47] Farley G, Jones R. Crushing characteristics of continuous fibre-reinforced composite tubes.International Journal of Composite Materials. 1992;26:37-50.

[48] Hull D. A unified approach to progressive crushing of fibre-reinforced composite tubes. Composites Science and Technology. 1991; 40:377-421.

[49] Mirzaei M, Shakeri M, Sadighi M, Akbarshahi H. Experimental and analytical assessment of axial crushing of circular hybrid tubes under quasi-static load. Composite Structures. 2012; 94:1959-66.

[50] Guler MA, Cerit ME, Bayram B, Gerçeker B, Karakaya E. The effect of geometrical parameters on the energy absorption characteristics of thin-walled structures under axial impact load. International Journal Crashworthiness. 2010; 15:377-90.

[51] Eshkoor RA, Ude AU, Oshkovr SA, Sulong AB, Zulkifli R, Ariffin AK, Azhari $\mathrm{CH}$. Failure mechanism of woven natural silk/epoxy rectangular composite tubes under axial quasi-static crushing test using trigger mechanism. International Journal of Impact Engineering. 2014; 64:53-61.

[52] Mahdi E, Sebaeya TA. An experimental investigation into crushing behaviour of radially stiffened GFRP composite tubes. Thin-walled structures. 2014; 76:8-13.

[53] Elfetori AE, Sulaiman S, Hamouda AMS, Mahdi E. Quasi-static axial and lateral crushing of radial corrugated composite tubes. Thin-walled structures. 2008; 46:320-32.

[54] Yan L, Chouw N. Crashworthiness characteristics of flax fibre reinforced epoxy tubes for energy absorption application. Materials \& Design. 2013; 51:629-40. 